Table 1. Mean Values of Twenty TaIL Tendon Fibres from fach of

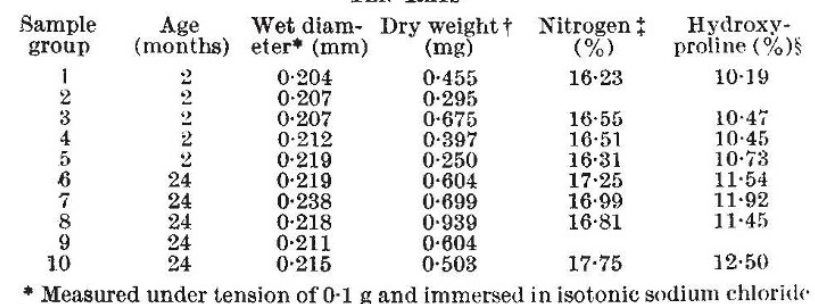
solution. All fibres were $5.0 \mathrm{~cm}$ long.

+ Dried to a constant weight in vacuo at $80^{\circ} \mathrm{C}$ for $12 \mathrm{~b}$.

¥ Performed in duplicate by combustion (Coleman nitrogen analyser). 1961 ).

Performed by the Woessner II method (Arch. Biochem. Biophys., 93, 440)

the swelling and extractability of human tendon decreased with age. This is evidence for an increased number of cross links in the native collagen of the old as compared to the young subjects. Tendon fibres from young animals are also more susceptible to destruction than tendon fibres of old animals because hydroxyproline is released more readily during hydrothermal shrinkage from the fibres of young than of old animals ${ }^{11}$.

Confusion about hydrothermal shrinkage persists bewause of the lack of a conceptual framework. Flory and his associates have now assembled abundant evidence to confirm that the hydrothermal shrinkage of collagen is a first order phase transition comparable to ordinary melting. When the phenomenon of hydrothermal shrinkage is investigated under equilibrium conditions, as was done here, age makes no difference. The present investigation confirms, on a gross scale, the similarity of collagen polypeptide chains derived from young and from old animals. Therefore, the effects of ageing can best be described as the rosult of forces lateral to the axis of the chain. It is interesting that, although tail tendon fibres from young and old rats had the same mean diameter in the wet state, there was twice as much collagen in the fibres from the old animals.

This work was supported in part by a grant from the National Institutes of Health, U.S. Public Health Service.

Noel W. Lawson Wilbur M. Griles John A. Pierce

Department of Medicine,

University of Arkansas Medical Center,

Little Rock.

'Ramachandran, G. N., Sasisekharan, V., and 'Thathachari, Y. 'T., in Collagen, Ramanathan, N., ed. (John Wiley, New York, 1962). 1. 2 Harding, J. J., Adr. Protein Chem., 20, 109 (1965).

Flory, P. J., and Spurr, O. K., J. Amer. Chem. Soc., 83, 1308 (1961).

' Rigby, B. J., Biochim. Biophys. Acta, 47, 534 (1961).

; Flory, P. J., J. Amer. Chem. Soc., 78, 5222 (1956).

${ }^{\text {B }}$ Spurr, jun., O. K., thesis, Cornell Univ. (1958).

: Weaver, E. S., thesis, Cornell Univ. (1959).

Dumitru, E. T., thesis, Cornell Univ. (1957).

- Theiss, E. K., and Serfass, E. J., J. Amer. Leather Chemists Assoc., 44, it +6 (1949).

${ }^{10}$ Banfield, W. F., J. Gerontol., 11, 372 (1956). Banfield, W. G., Anat. Aiec, 114, 157 (1952).

${ }^{*}$ Verzar, F., and Meyer, A., Gerontologia, 5, 163 (1961).

\section{Fluorescent Properties of the Non-collagenous Components of the Intervertebral Disk}

IT has previously been shown, chiefly by $\mathrm{X}$-ray diffraction, that the intercellular matrices of connective tissues contain four main non-collagenous proteins in addition to collagen fibrils ${ }^{1,2}$. Three of these proteins occur as major components of the intervertebral disks. They have been provisionally described as: $(a)$ An immature $\beta$-protein, which is present in infants and young children. (b) A mature $\beta$-protein, present in adolescents and in increasing proportions in middle age. This protein is also produced in quantity in prolapsed disk tissue. (c) A dense $\beta$-protein which, in normal disks, is present in increasing quantity from about age $45-50$ onwards. In other tissues, such as the ligamentum flavum, elastic tissue is also present.

These non-collagenous proteins have been satisfactorily distinguished by their X-ray diffraction patterns, but this method involved using samples about $1 \mathrm{~mm}$ in diameter. The non-collagenous proteins fluoresee with ultra-violet light, and we decided to investigate this property further. Fluorescent examination, both macroscopic and microscopic, is potentially a quicker, easier and more specific method of investigation. 'The ultra-violet source used was a 'Philips H.P.W.' 125-W lamp, type 57236 F/70. The fluorescent radiation from each of the proteins was observed to have a slightly different colour. These are tabulated in Table 1.

$\begin{array}{lc} & \text { T'able } 1 \\ \text { Protein } & \text { ('olour under ultra-violet light } \\ \text { Immature } \beta \text {-protein } & \text { Purplish-blue } \\ \text { Mature } \beta \text {-protein } & \text { Blue } \\ \text { Dense } \beta \text {-protein } & \text { Whitish-blue } \\ \text { Elastic tissue } & \text { Greenish-blue }\end{array}$

When the specimens were allowed to dry, the intensity of fluorescent radiation produced by the immature and mature $\beta$-protein decreased. A further observation was that disk tissue from young individuals, which contains the immature $\beta$-protein, shrank considerably more than the tissue from older individuals.

It was uncertain how much these different swelling and shrinking properties were associated with the proteins, and how much was due to the accompanying polysaccharides; but the fact that the two compounds which give the less well ordered X-ray diffraction patterns are in tissues which shrink more, and which also tend to lose some of their fluoreseence on drying, suggests stronglythat the loss is a concentration quenching effect. This would mean that the protein molecules could only have a very loose cross-linking, and that it would be more correct to consider the tissues as resilient gels, although the more ordered mature $\beta$-protein almost certainly has properties like those of rubber. The lack of a quenching effect in the other two proteins, the dense $\beta$-protein and elastic tissue, would suggest a smaller molecular re-ordering on drying, which is in accord with their rubber-like physical properties. Elastic tissue has already been shown to contain many cross-linkages ${ }^{3}$.

This interpretation, that the tissues in the intervertebral disk are in the form of a resilient gel in the younger age groups, and undergo a change to a rubberlike structure in middle age, would account for the fact that prolapse of lumbar disks is a disease of the young adult. Cell death in a gel typo of matrix, with lack of production of the essential polysaccharide components of the gel, would lead to collapse of the gel structure, and so to the onset of prolapse; a similar event in a tissue with a rubbery texture would not be expected to affect the basic structure of the matrix.

\section{A. Moschi K. LitTt.e}

Nuffield Department of Orthopaedic Surgery, Oxford.

${ }_{1}^{1}$ Little, K., and Taylor, T. K. F., Age with a Futrere, 311 (Munksgaard, 1964). ${ }_{2}^{2}$ Taylor, T. K. F., and Little, K., Nature, 208, 384 (1965).

${ }^{3}$ Partridge, S. M., Elsden, D. F., and Thomas, J., Nature, 197, 1297 (1963).

\section{Dependence of the Oxygen Effect on the Energy of Fast Neutrons}

THE extent to which oxygen enhances radiation damage in biological systems is known to depend on the typo of radiation used ${ }^{1-4}$. Quantitatively, this effect may be represented by the oxygen enhancement ratio (OER). which is defined as the ratio between the doses of radiation required to produce equal degrees of damage in anoxic and oxygenated cells ${ }^{5}$. High values of the OER, 